\title{
Hydration requirements with emetogenic chemotherapy: granisetron extended-release subcutaneous versus palonosetron
}

\author{
Jeffrey Vacirca*,1, Dennis Caruana ${ }^{1}$, George Calcanes ${ }^{1}$, Michael Mosier ${ }^{2}$, Ralph Boccia ${ }^{3} \&$ \\ Ali McBride ${ }^{4}$ \\ ${ }^{1}$ New York Cancer \& Blood Specialists, 235 N Belle Mead Rd, East Setauket, NY 11733, USA \\ ${ }^{2}$ EMB Statistical Solutions, LLC, 55 Corporate Woods, 9300 West 110th Street, Suite 550, Overland Park, KS 66210, USA \\ ${ }^{3}$ Center for Cancer \& Blood Disorders, 6410 Rockledge Dr, Suite 660, Bethesda, MD 20817, USA \\ ${ }^{4}$ University of Arizona Cancer Center, 3838 N Campbell Ave, Tucson, AZ 85719, USA \\ *Author for correspondence: Tel.: +1 631675 5290; Fax: +1 631675 2610; jvacirca@yahoo.com \\ Prior presentation: presented as a poster at the 2017 ASCO Palliative \& Supportive Care in Cancer Symposium.
}

Aim: This retrospective analysis evaluated chemotherapy-induced nausea and vomiting (CINV)-related hydration needs with palonosetron or granisetron extended-release subcutaneous (GERSC), approved in 2016 for CINV prevention. Materials \& methods: At a community practice, CINV-related hydration per chemotherapy cycle was determined following highly (HEC) or moderately emetogenic chemotherapy (MEC) and a guideline-recommended antiemetic regimen: NK-1 receptor antagonist, dexamethasone and either palonosetron only, GERSC only, or palonosetron switched to GERSC. Results: Palonosetron-only patients $(n=93)$ had a significantly higher mean (standard deviation) hydration rate (0.9 [1.1]) than GERSConly patients $(n=91 ; 0.3[0.6] ; p<0.0001)$. Switched patients' $(n=48)$ hydration rates were significantly higher in the HEC subgroup with palonosetron (0.7 [1.2]) versus GERSC (0.5 [1.0]; $p=0.028)$. Conclusion: GERSC in a three-drug antiemetic regimen may reduce hydration needs following HEC or MEC.

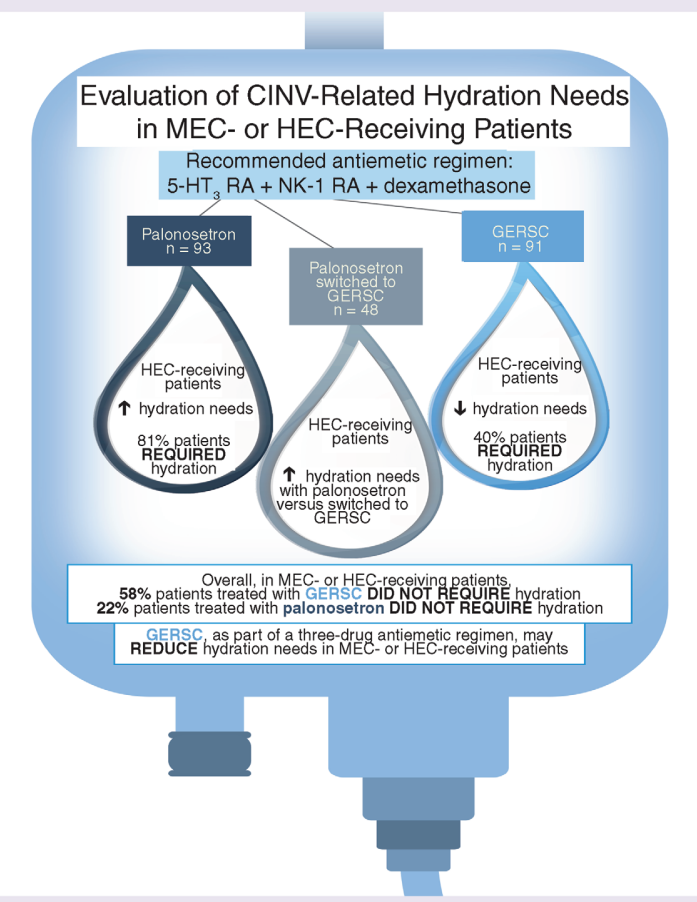

CINV: Chemotherapy-induced nausea and vomiting; GERSC: Granisteron extended-release subcutaneous; HEC: Highly emetogenic chemotherapy; MEC: Moderately emetogenic chemotherapy. 
First draft submitted: 20 December 2017; Accepted for publication: 16 January 2018; Published online: 9 February 2018

Keywords: chemotherapy-induced nausea and vomiting $\bullet$ CINV • GERSC • granisetron extended-release subcutaneous $\bullet$ hydration

Poorly controlled chemotherapy-induced nausea and vomiting (CINV) negatively affects patient health, quality of life and chemotherapy compliance [1-7], and is associated with increased resource utilization and healthcare costs [7-10]. Despite comprehensive antiemetic treatment guidelines [11-14], there is still an unmet clinical need to improve the prevention of CINV.

Clinical practice guidelines recommend a combination of antiemetics of different classes for the prevention of CINV, including 5-hydroxytryptamine type $3\left(5-\mathrm{HT}_{3}\right)$ receptor antagonists, $\mathrm{NK}-1$ receptor antagonists and dexamethasone [11-14]. Granisetron and palonosetron are two of several 5- $\mathrm{HT}_{3}$ receptor antagonist antiemetics included in antiemetic guidelines [11-14]. A recent addition to this class is granisetron extended-release subcutaneous (GERSC; Sustol ${ }^{\circledR}$ ), a novel formulation of $2 \%$ granisetron in a viscous bioerodible Biochronomer ${ }^{\circledR}$ tri(ethylene glycol) poly(orthoester) (TEG-POE) polymer [15]. After subcutaneous administration into the upper arm or abdomen, the polymer undergoes controlled, sustained hydrolysis maintaining therapeutic concentrations of granisetron for $\geq 5$ days [16]. A single dose of GERSC (granisetron $10 \mathrm{mg}$ ) provides extended release of granisetron for the prevention of both acute (0-24 h after chemotherapy) and delayed (24-120 h) CINV [16]. In a Phase III noninferiority trial in combination with dexamethasone, GERSC $500 \mathrm{mg}$ was noninferior to intravenous (iv.) palonosetron $0.25 \mathrm{mg}$ in controlling acute CINV in patients receiving moderately (MEC) or highly emetogenic chemotherapy (HEC) and in preventing delayed CINV in patients receiving MEC [17,18]. Both treatments were well tolerated. Treatment-related injection site reactions (primarily bruising) occurred more frequently in patients who received GERSC than in those who received palonosetron, but these events were generally mild and resolved over time [17,18]. In the Phase III MAGIC trial comparing GERSC with ondansetron, each in a three-drug regimen with an NK-1 receptor antagonist and dexamethasone, GERSC was superior to ondansetron in complete response (no emesis or rescue medication) during the delayed phase of CINV in patients receiving HEC [19]. Both agents were well tolerated, and the incidence of injection site reactions was similar in both treatment groups [19]. GERSC is approved by the US FDA for use in combination with other antiemetics for the prevention of acute and delayed nausea and vomiting associated with initial and repeat courses of MEC or anthracycline and cyclophosphamidebased regimens [20]. It is recommended by the National Comprehensive Cancer Network antiemesis guidelines as a $5-\mathrm{HT}_{3}$ receptor antagonist option for use in combination with dexamethasone and an NK-1 receptor antagonist for the prevention of CINV associated with $\mathrm{HEC}$ and as a preferred $5-\mathrm{HT}_{3}$ receptor antagonist for use in combination with dexamethasone for the prevention of CINV associated with MEC [11]. To our knowledge, GERSC is the only $5-\mathrm{HT}_{3}$ receptor antagonist to demonstrate superiority over another $5-\mathrm{HT}_{3}$ receptor antagonist (ondansetron) in a three-drug versus three-drug pivotal Phase III trial [19].

Breakthrough CINV can occur in up to $40 \%$ of patients, despite the use of guideline-recommended prophylactic antiemetic regimens [21]. Treatment includes the use of 'rescue' antiemetic medication from another antiemetic class, hydration and correction of electrolyte abnormalities, and patients may even require hospitalization [11,21]. The costs of uncontrolled CINV can be substantial, including both direct medical costs and associated indirect costs, such as patients' inability to work and overall quality of life $[8,10]$. This retrospective analysis evaluated CINV-related hydration among patients receiving MEC or HEC and CINV prophylaxis at a community-based practice.

\section{Materials \& methods \\ Patients \& treatments}

At a single community-based multi-site practice with 24 locations, consecutive patients who met the following criteria were included in the analysis: patients with cancer who were scheduled to receive MEC or HEC and a recommended three-drug antiemetic regimen of a NK-1 receptor antagonist, dexamethasone and one of three specific $5-\mathrm{HT}_{3}$ receptor antagonist therapies: palonosetron (Aloxi ${ }^{\circledR}$ ) only, GERSC as initial therapy or palonosetron first then switched to GERSC and continued on GERSC. Data were extracted from each patient's electronic medical record, including demographic information, cancer diagnosis, Eastern Cooperative Oncology Group performance status, the emetogenic potential of the chemotherapy regimen (HEC or MEC) administered, the number of 


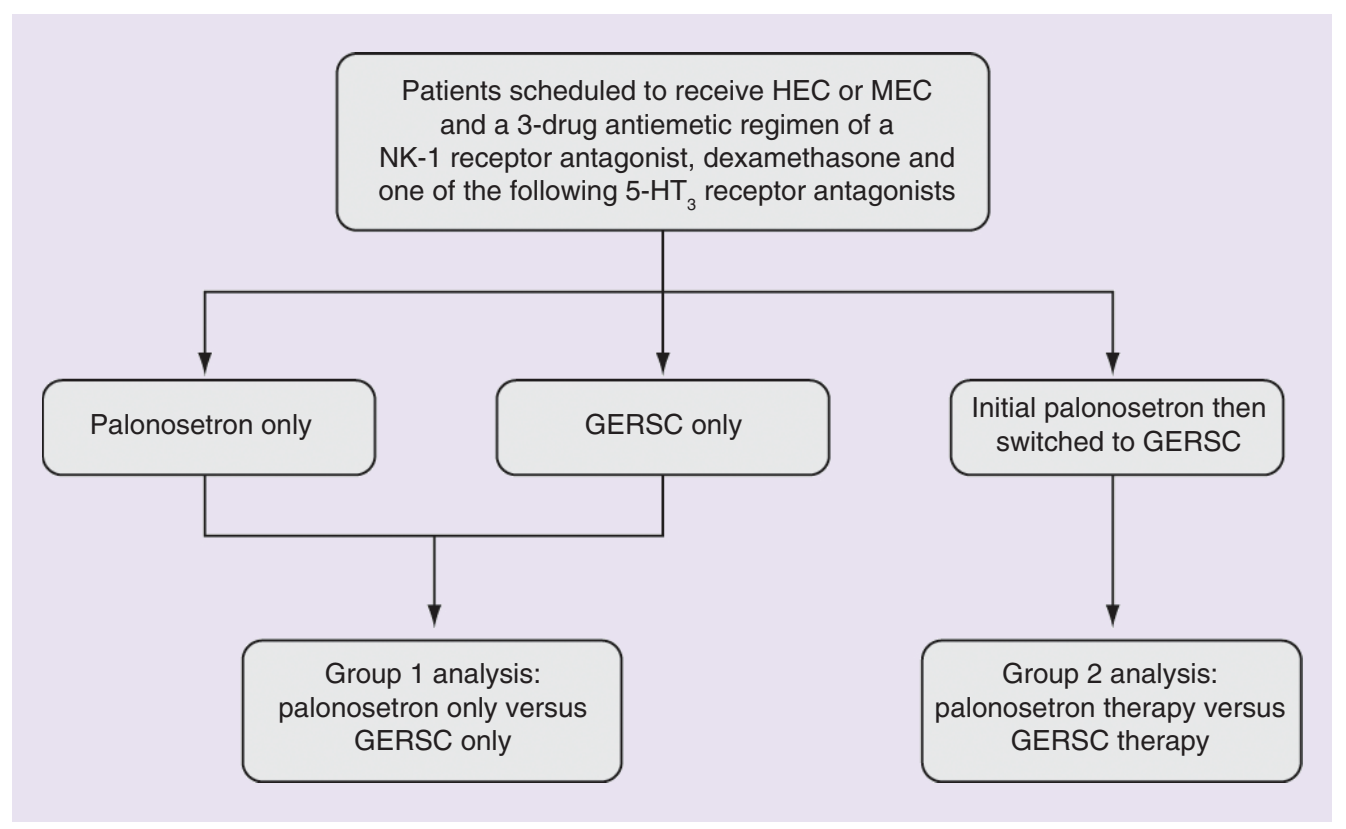

Figure 1. Study design.

GERSC: Granisetron extended-release subcutaneous; HEC: Highly emetogenic chemotherapy; MEC: Moderately emetogenic chemotherapy.

chemotherapy cycles received, whether concomitant radiation therapy was administered and the CINV-related hydration requirements at each cycle of chemotherapy.

\section{Study objective}

The objective of this retrospective analysis was to determine the proportion of patients requiring CINV-related hydration per chemotherapy cycle in each of the three treatment groups overall and by the emetogenicity of their chemotherapy regimen. Comparisons were made between patients who received palonosetron only, GERSC only and those who switched from palonosetron to GERSC. Patients were switched from palonosetron to GERSC based upon a decision by the practice to use GERSC as the preferred 5- $\mathrm{HT}_{3}$ RA for both MEC and HEC, and not due to a poor initial response to palonosetron.

\section{Statistical analyses}

The main end point was hydration use, which was computed as the number of unscheduled hydration therapies per chemotherapy cycle to account for differing numbers of chemotherapy cycles received between groups. Two analyses were performed: the group 1 analysis was a comparison of patients who received palonosetron only versus GERSC only; and the group 2 analysis was a comparison of patients who received palonosetron therapy initially but were then switched to GERSC and continued on GERSC (Figure 1). For the group 1 analysis, a nonparametric two-sided Wilcoxon rank sum test with $\alpha=0.05$ was used to test the null hypothesis of no difference between groups in hydration rate, as distribution of the rate variable is extremely right-skewed. The group 2 analysis was conducted using a paired t-test.

\section{Results}

\section{Patient disposition \& characteristics}

The study population included 93 patients treated with palonosetron only during the period January 2016-June 2017, 91 patients who received GERSC only during October 2016-June 2017 and 48 patients who received palonosetron first then switched to GERSC during May 2016-May 2017.

Patient demographics and clinical characteristics of patients are shown in Table 1. Most patients in each treatment group were women $(68-71 \%)$, and the most common cancer types were lung cancer in the palonosetron- or GERSC-only groups (31 and 24\%, respectively) and breast cancer in the switched group (23\%). All patients 
Table 1. Patient demographics and baseline characteristics.

\begin{tabular}{|c|c|c|c|}
\hline & Palonosetron only; $\mathrm{n}=93$ & GERSC only; $\mathbf{n}=91$ & Switched (palonosetron to GERSC); $n=48$ \\
\hline Age; mean (min, max), years & $65(39,90)$ & $63(32,87)$ & $65(32,84)$ \\
\hline \multicolumn{4}{|l|}{ Sex; n (\%) } \\
\hline Men & $30(32)$ & $26(29)$ & $15(31)$ \\
\hline Women & $63(68)$ & $65(71)$ & $33(69)$ \\
\hline \multicolumn{4}{|l|}{ Cancer type; n (\%) } \\
\hline Breast & $19(20)$ & $18(20)$ & $11(23)$ \\
\hline Gastrointestinal & $9(10)$ & $21(23)$ & $9(19)$ \\
\hline Genitourinary & $4(4)$ & $2(2)$ & $1(2)$ \\
\hline Gynecologic & $16(17)$ & $10(11)$ & $10(21)$ \\
\hline Leukemia/lymphoma & $11(12)$ & $15(17)$ & $8(17)$ \\
\hline Other & $5(5)$ & $3(3)$ & $4(8)$ \\
\hline Yes & $23(25)$ & $12(13)$ & $5(10)$ \\
\hline Antiemetic regimen & $\begin{array}{l}\text { Palonosetron } 0.25 \mathrm{mg} \text { iv. } \\
\text { + fosaprepitant } 150 \mathrm{mg} \text { iv. } \\
\text { + dexamethasone } 10 \mathrm{mg}^{\dagger}\end{array}$ & $\begin{array}{l}\text { GERSC } 10 \mathrm{mg} \mathrm{sc} \text { + fosaprepitant } 150 \mathrm{mg} \\
\text { iv. + dexamethasone } 10 \mathrm{mg}^{\dagger}\end{array}$ & $\begin{array}{l}\text { Palonosetron } 0.25 \mathrm{mg} \text { iv. + aprepitant } \\
150 \mathrm{mg} \text { iv. + dexamethasone } 10 \mathrm{mg} \text {, then } \\
\text { GERSC } 10 \mathrm{mg} \text { sc. } \\
+ \text { aprepitant } 150 \mathrm{mg}+\text { dexamethasone } \\
10 \mathrm{mg}^{\dagger}\end{array}$ \\
\hline
\end{tabular}

received aprepitant $150 \mathrm{mg}$ iv. and dexamethasone $10 \mathrm{mg}$ in addition to either palonosetron $0.25 \mathrm{mg}$ iv. or GERSC 10 mg subcutaneously.

The most common chemotherapy regimens were carboplatin (area under the concentration-time curve of six in most cases $)+$ paclitaxel in the palonosetron-only group $(\mathrm{n}=12)$ and cyclophosphamide, doxorubicin, vincristine and rituximab in the switched group $(n=6)$. In the GERSC-only group, two different regimens were administered to nine patients each: carboplatin + etoposide and doxorubicin + cyclophosphamide + paclitaxel. In group 1, $78 / 93$ patients $(84 \%)$ treated with palonosetron and 55/91 patients $(60 \%)$ treated with GERSC initially received HEC. In group 2, $32 / 48$ patients $(67 \%)$ who were switched from palonosetron to GERSC received HEC.

In group 1, because the observation period was longer for patients receiving palonosetron only, than for patients receiving initial GERSC, the mean (standard deviation [SD]) number of chemotherapy cycles was 5.4 (2.8) for patients receiving initial palonosetron and 4.1 (2.2) for patients receiving initial GERSC. In group 2, the switched patients received a mean (SD) of 3.5 (3.2) chemotherapy cycles while on palonosetron and 3.1 (2.2) while on GERSC (Table 2).

\section{Hydration analyses}

Each hydration event was typically $500 \mathrm{ml}$ of $0.9 \%$ normal saline planned to be administered iv. over $3 \mathrm{~h}$. For the group 1 analysis, patients receiving palonosetron had a significantly higher mean (SD) number of hydration events per chemotherapy cycle (0.9 [1.1]) compared with patients receiving initial GERSC $(0.3$ [0.6]; $p<0.0001)$ (Table 2). Overall, 58\% of patients treated with GERSC only did not require any hydration, compared with $22 \%$ of patients treated with palonosetron only (Figure 2). For the subgroup of patients receiving HEC, patients receiving palonosetron had a significantly higher mean number of hydration events per cycle (1.0) than patients receiving GERSC (0.3) ( $\mathrm{p}<0.0001)$, whereas for the MEC subgroup, the difference in hydration rates between the palonosetron and GERSC groups approached statistical significance $(0.5$ vs 0.3 , respectively; $\mathrm{p}=0.0686)($ Table 2$)$. In patients receiving $\mathrm{HEC}$ or MEC, 40 and 44\% of patients, respectively, treated with initial GERSC required hydration, whereas 81 and $67 \%$ of patients, respectively, treated with initial palonosetron required hydration (Figure 3). 
Table 2. Group 1 analysis: number of chemotherapy cycles and hydration rate.

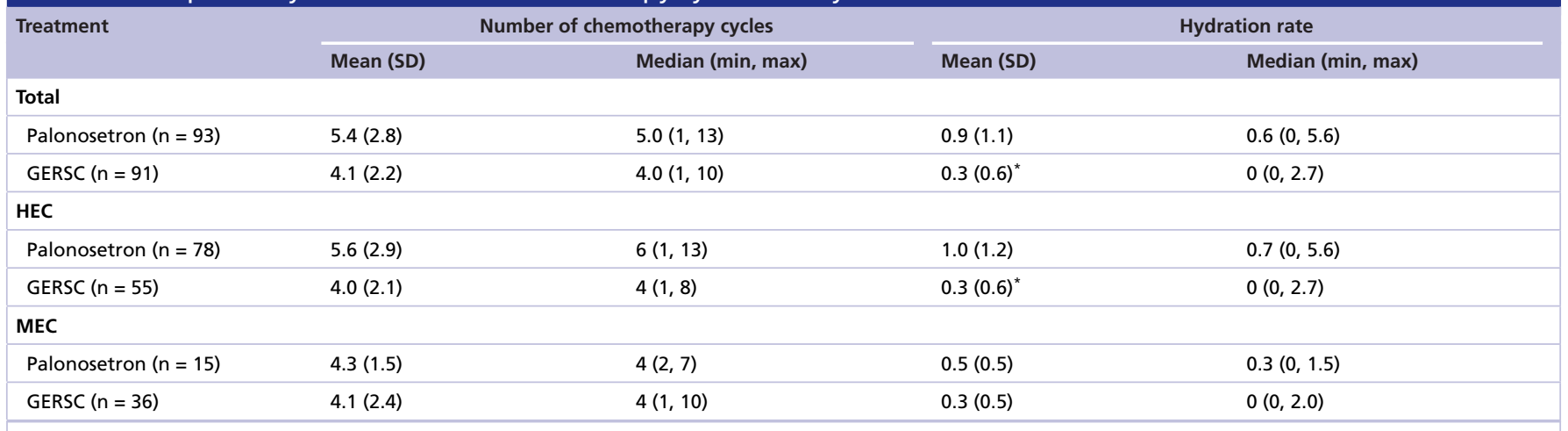

${ }^{*} p<0.0001$ for the difference in hydration rate versus palonosetron.

GERSC: Granisetron extended-release subcutaneous; HEC: Highly emetogenic chemotherapy; max: Maximum; MEC: Moderately emetogenic chemotherapy; min: Minimum; SD: Standard deviation.

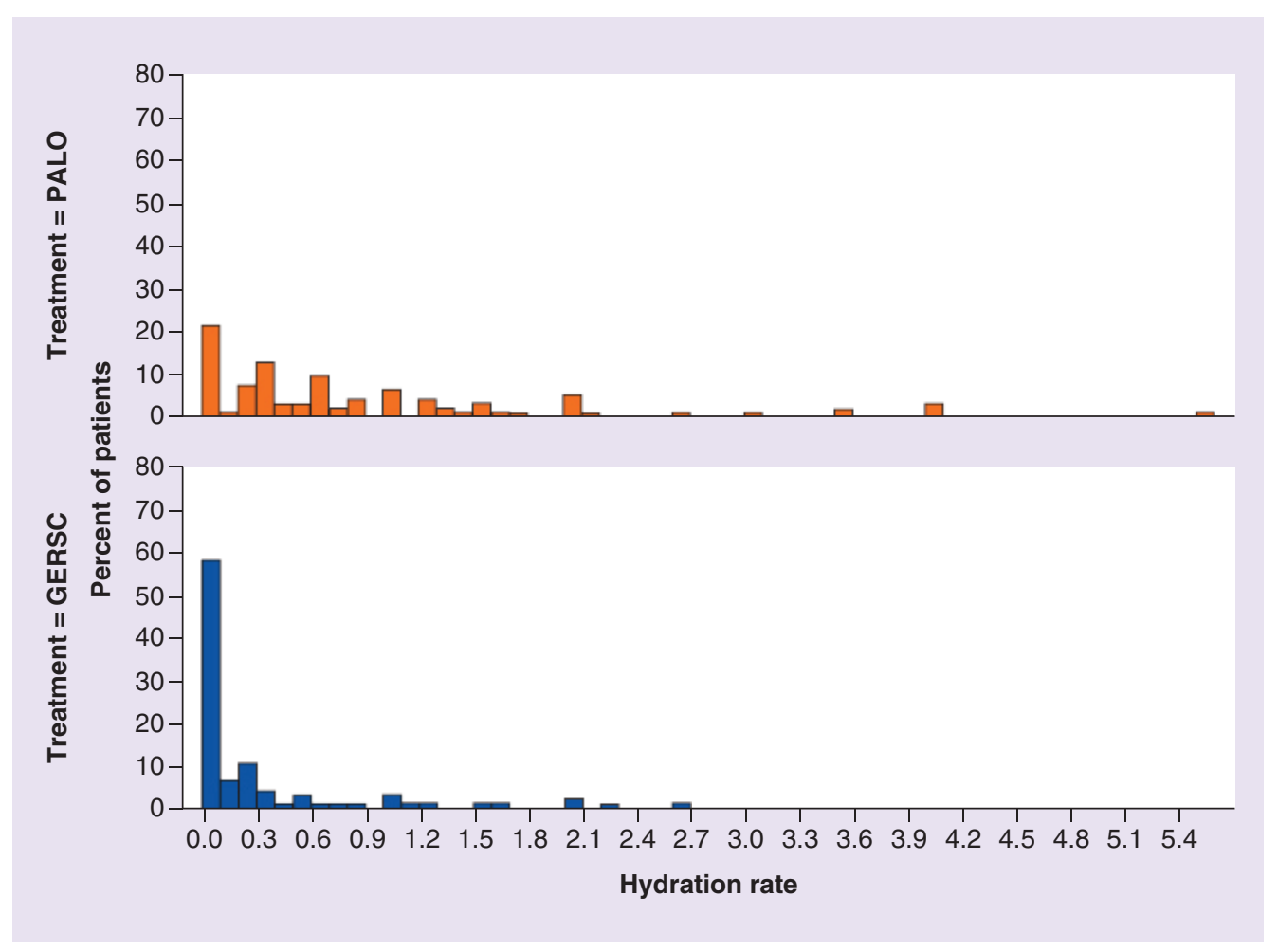

Figure 2. Group 1 analysis. Distribution of hydration rate by chemotherapy cycle and by antiemetic regimen. GERSC: Granisetron extended-release subcutaneous; PALO: Palonosetron.

For the group 2 analysis, there was no significant difference in the mean (SD) number of hydration events per cycle when patients received palonosetron $(0.6$ [1.1]) compared with when they received GERSC (0.5 [1.1]; $\mathrm{p}=0.127$ ) (Table 3). Similarly, for the MEC subgroup there was no significant difference in the mean (SD) number of hydration events per cycle when patients were receiving palonosetron $(0.5$ [0.9]) compared with when they were receiving GERSC (0.6 [1.3]; $\mathrm{p}=0.852)$. For the HEC subgroup, hydration rates were significantly higher when patients were treated with palonosetron $(0.7$ [1.2]) compared with when they were switched to GERSC (0.5 [1.0]; $\mathrm{p}=0.028)$ (Table 2). 


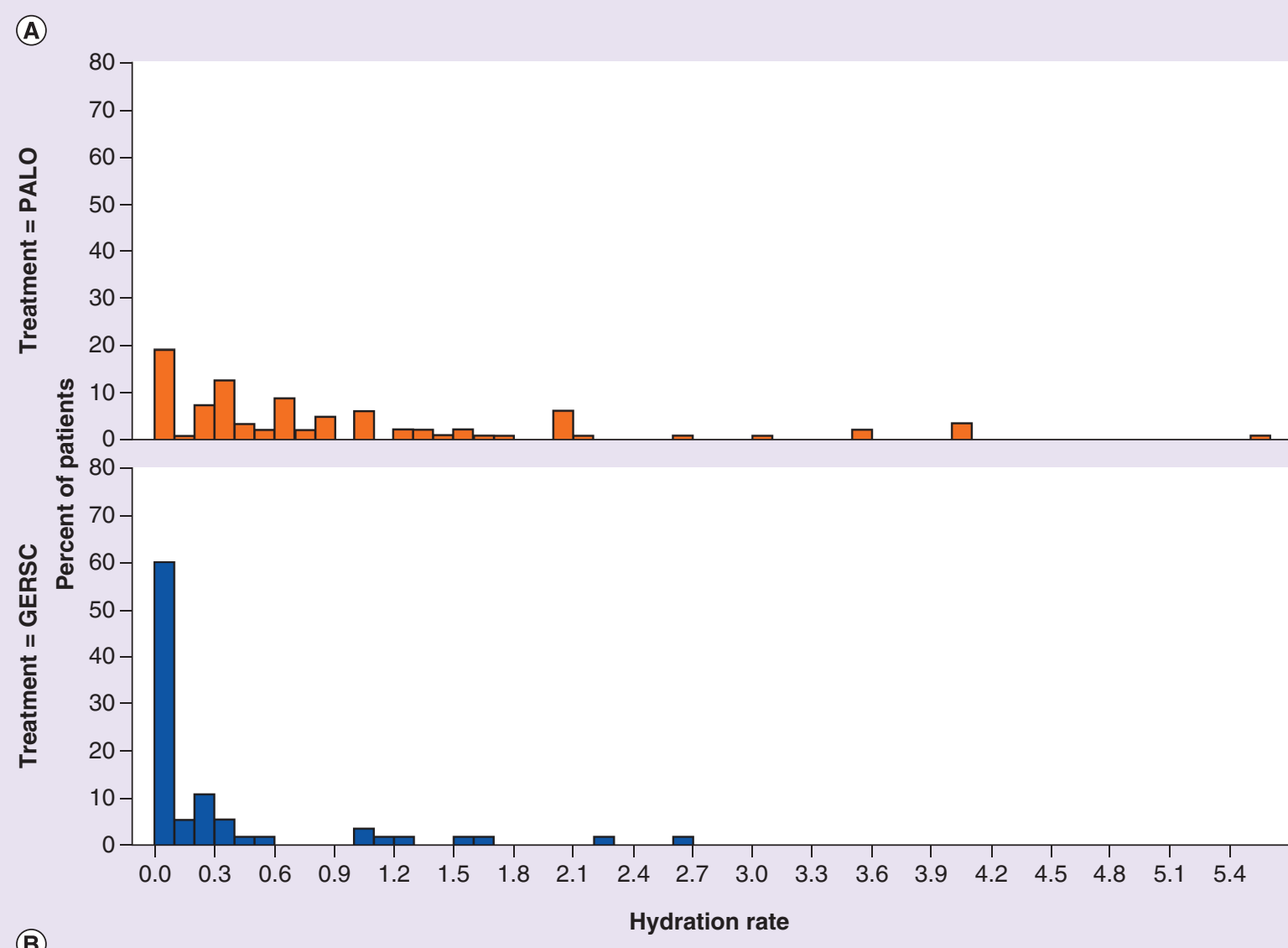

(B)

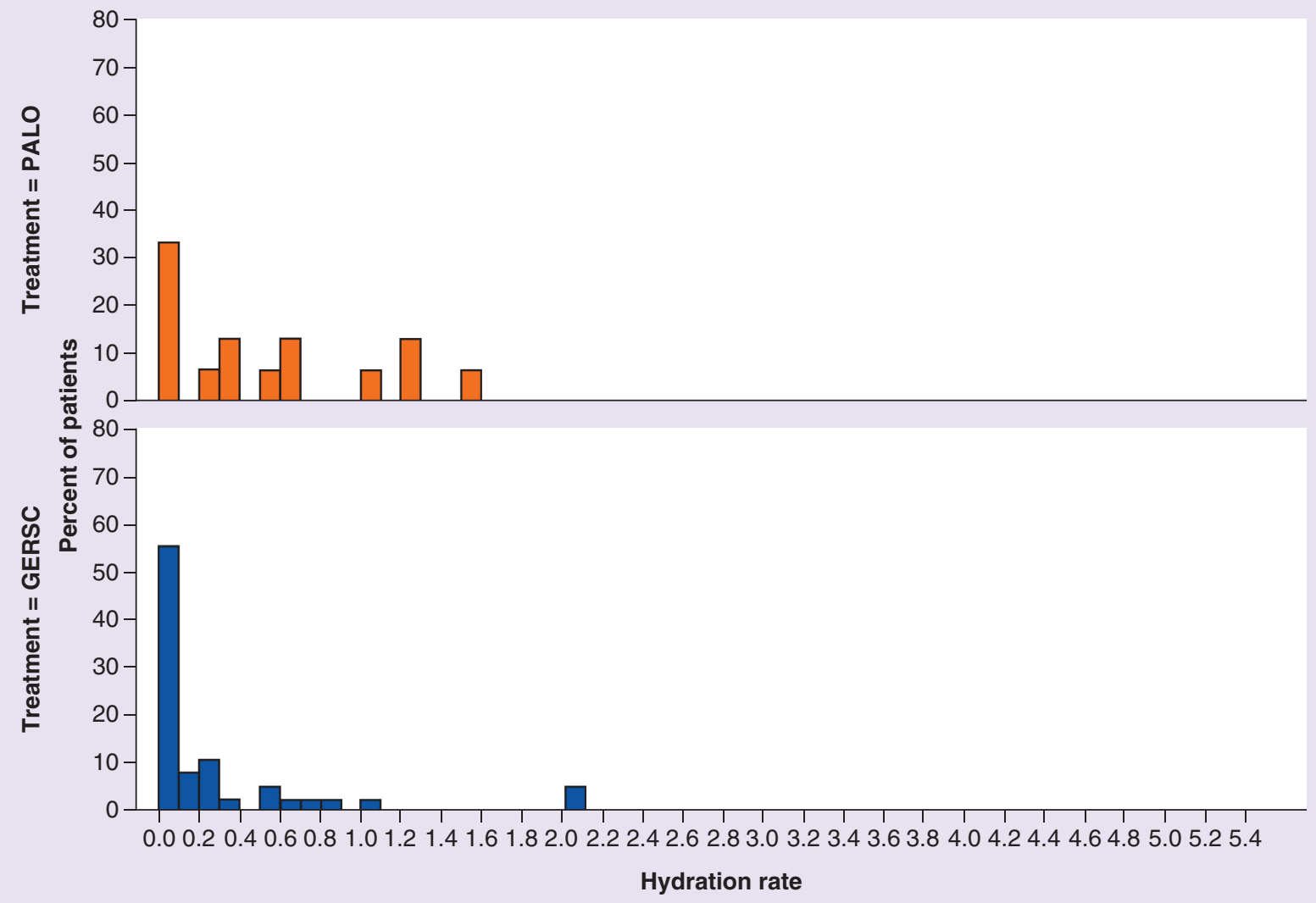

Figure 3. Group 1 analysis. Distribution of hydration rates by chemotherapy cycle and by antiemetic regimen for patients receiving (A) highly emetogenic chemotherapy or (B) moderately emetogenic chemotherapy. GERSC: Granisetron extended-release subcutaneous; PALO: Palonosetron. 


\begin{tabular}{|c|c|c|c|c|}
\hline \multirow[t]{2}{*}{ Treatment } & \multicolumn{2}{|c|}{ Number of chemotherapy cycles } & \multicolumn{2}{|c|}{ Hydration rate } \\
\hline & Mean (SD) & Median (min, max) & Mean (SD) & Median (min, max) \\
\hline Palonosetron $(n=48)$ & $3.5(3.2)$ & $2.0(1,13)$ & $0.6(1.1)$ & $0.2(0,5.3)$ \\
\hline $\operatorname{GERSC}(n=48)$ & $3.1(2.2)$ & $3.0(1,11)$ & $0.5(1.1)$ & $0(0,5.0)$ \\
\hline \multicolumn{5}{|l|}{ HEC } \\
\hline $\operatorname{GERSC}(n=32)$ & $2.9(2.0)$ & $2.5(1,9)$ & $0.5(1.0)^{\star}$ & $0(0,5.0)$ \\
\hline \multicolumn{5}{|l|}{ MEC } \\
\hline Palonosetron $(n=16)$ & $3.9(3.3)$ & $3.0(1,11)$ & $0.5(0.9)$ & $0.2(0,3)$ \\
\hline GERSC $(n=16)$ & $3.7(2.7)$ & $3.5(1,11)$ & $0.6(1.3)$ & $0(0,5)$ \\
\hline
\end{tabular}

${ }^{*} p=0.028$ for the difference in hydration rate versus palonosetron.

GERSC: Granisetron extended-release subcutaneous; HEC: Highly emetogenic chemotherapy; max: Maximum; MEC: Moderately emetogenic chemotherapy; min: Minimum; SD: Standard deviation.

\section{Discussion}

In this retrospective analysis at a community-based multi-site practice, medical records were evaluated of patients with cancer who were scheduled to receive MEC or HEC and a recommended three-drug antiemetic regimen of an NK-1 receptor antagonist, dexamethasone and one of the three specific 5- $\mathrm{HT}_{3}$ receptor antagonist therapies: palonosetron only, GERSC as initial therapy or palonosetron first then switched to GERSC and continued on GERSC. The primary objective was to evaluate CINV-related hydration requirements during each cycle of chemotherapy.

Patients receiving HEC or MEC who received initial therapy with GERSC as part of a three-drug antiemetic regimen required approximately three-times fewer CINV-related hydration events per chemotherapy cycle than patients who received initial therapy with palonosetron as part of a three-drug antiemetic regimen, a significant difference in favor of GERSC. This finding may have been confounded by the fact that more patients treated with initial palonosetron (84\%) versus initial GERSC $(60 \%)$ received HEC. However, when comparing the subgroup of patients who received HEC, a significant difference between treatment groups was also found, as approximately three-times fewer hydration events occurred in patients treated with initial GERSC versus initial palonosetron. The subgroup receiving MEC had approximately half the number of hydration events in patients treated with initial GERSC versus initial palonosetron, with this difference approaching statistical significance. Patients who received palonosetron as part of their three-drug antiemetic regimen required almost one hydration session for every chemotherapy cycle administered. Overall, 1.5- to two-times more patients receiving initial palonosetron required hydration during the observation period, compared with patients receiving initial GERSC.

In the group of patients that was switched from palonosetron to GERSC as part of a three-drug antiemetic regimen, there was no significant difference in hydration requirements overall or when patients received MEC, but hydration events were significantly lower when patients receiving HEC were switched from palonosetron to GERSC. This analysis is of particular interest since these HEC patients served as their own controls, initially requiring more hydrations per chemotherapy cycle with palonosetron and then requiring fewer with GERSC, without any change in their chemotherapy regimens.

Despite the availability of a range of antiemetic agents and comprehensive guidelines for the prevention of CINV using combinations of antiemetic agents, there is still an opportunity to optimize the use of available agents to provide better control of CINV. Breakthrough CINV has been reported in up to $40 \%$ of patients, even using guideline-recommended prophylactic antiemetic regimens [21]. Suboptimal control of CINV increases resource utilization, including CINV-related office visits and hospital and emergency room visits [10]. In a systematic literature review, all economic studies reviewed were in agreement that poorly controlled CINV remains a problem, leading to increases in both direct costs (e.g., clinic, hospital and emergency room visits; rescue medication) and indirect costs (e.g., patient work days lost) [7]. A recent retrospective analysis of data from US Agency for Healthcare Research and Quality's Healthcare Cost and Utilization Project website reported that there were 37,730 hospital discharges for nausea and vomiting in 2014, with mean charges of US\$23,603 per visit, including both hospital costs and physician fees [22]. Furthermore, failure to control CINV also has a considerable negative effect on patients' quality of life, even in patients receiving MEC, highlighting the need for early and effective CINV prevention [7]. 
The reductions in the number of hydration events with GERSC compared with palonosetron, observed in the current analysis, would be expected to be associated with reduced healthcare costs for hydration for patients who received GERSC as the $5-\mathrm{HT}_{3}$ receptor antagonist in a three-drug antiemetic regimen, compared with patients who received palonosetron. Moreover, the control of breakthrough CINV and reduced hydration needs observed with GERSC in the current analysis may improve patient quality of life and simplify patient management.

Limitations of this analysis include its retrospective nature, and the fact that patients were from a single multi-site community-based practice in the USA with 39 practicing physicians; however, the patient population was diverse, and included patients with various tumor types and receiving a range of chemotherapy regimens.

\section{Conclusion}

In conclusion, the use of GERSC as part of a three-drug antiemetic regimen may reduce the need for hydration in patients receiving HEC or MEC.

\section{Summary points}

- Poorly controlled chemotherapy-induced nausea and vomiting (CINV) negatively affects patients' quality of life and increases resource utilization.

- Despite comprehensive antiemetic guidelines, there is still an unmet clinical need to improve CINV prevention.

- Granisetron extended-release subcutaneous (GERSC) is a novel formulation of granisetron in a bioerodible polymer and was approved in August 2016, in combination with other antiemetics, for CINV prevention.

- In this retrospective analysis at a community-based multi-site oncology practice, CINV-related hydration was evaluated in patients receiving highly (HEC) or moderately emetogenic chemotherapy (MEC) and CINV prophylaxis with either palonosetron or GERSC, each as part of a guideline-recommended three-drug antiemetic regimen with a NK-1 receptor antagonist and dexamethasone.

- Comparisons were made between patients who received palonosetron only or GERSC only, and between patients who were switched from palonosetron to GERSC.

- The proportion of patients requiring CINV-related hydration per chemotherapy cycle was determined for each of the three antiemetic regimens overall and by HEC/MEC subgroups. Comparisons were made between patients who received palonosetron only versus GERSC only and those who were switched from palonosetron to GERSC.

- Patients in the GERSC-only group required approximately three-times fewer CINV-related hydration events per chemotherapy cycle than patients who received palonosetron only, a significant difference in favor of GERSC; $58 \%$ of GERSC recipients required no hydration compared with $22 \%$ of palonosetron recipients.

- For patients who were switched from palonosetron to GERSC, there was no significant difference in the mean number of hydration events per cycle when patients received palonosetron versus GERSC, but hydration rates were significantly higher in the HEC subgroup when patients received palonosetron than when they were switched to GERSC.

- GERSC as part of a three-drug antiemetic regimen may reduce hydration needs in patients receiving HEC or MEC.

Financial \& competing interests disclosure

J Vacirca reports stock ownership from Odonate Therapeutics, and has been a consultant/advisor for Heron Therapeutics and ION. D Caruana is employed by North Shore Hematology/Oncology Associates, PC, a division of New York Cancer \& Blood Specialists, and has received compensation for travel and accommodations from Oncopeptides AB. G Calcanes is employed and has a leadership role at North Shore Hematology/Oncology Associates, PC, a division of New York Cancer \& Blood Specialists. M Mosier has been a consultant/advisor for Heron Therapeutics. R Boccia is employed and has a leadership role at Center for Cancer and Blood Disorders; has been a consultant/advisor for Gilead, Heron Therapeutics, Incyte and Otsuka; has been part of a speaker's bureau and received honoraria and compensation for travel and accommodations from AbbVie, Amgen, AstraZeneca, BMS, Celgene, DSI, Genentech, Gilead, Heron Therapeutics and Incyte; and his practice has received research funding from Incyte. A McBride has received honoraria from Heron Therapeutics. The authors have no other relevant affiliations or financial involvement with any organization or entity with a financial interest in or financial conflict with the subject matter or materials discussed in the manuscript apart from those disclosed.

Medical writing support was provided by YE Yarker of SciStrategy Communications, and funded by Heron Therapeutics, Inc. 
Ethical conduct of research

The authors state they have followed the principles outlined in the Declaration of Helsinki in order to conduct a minimal-risk, retrospective investigation of human subjects for whom collection of informed consent was waived.

\section{Open access}

This work is licensed under the Attribution-NonCommercial-NoDerivatives 4.0 Unported License. To view a copy of this license, visit http://creativecommons.org/licenses/by-nc-nd/4.0/

\section{References}

Papers of special note have been highlighted as: $\bullet$ of interest

1 Bloechl-Daum B, Deuson RR, Mavros P, Hansen M, Herrstedt J. Delayed nausea and vomiting continue to reduce patients' quality of life after highly and moderately emetogenic chemotherapy despite antiemetic treatment. J. Clin. Oncol. 24(27), 4472-4478 (2006).

2 Cohen L, De Moor CA, Eisenberg P, Ming EE, Hu H. Chemotherapy-induced nausea and vomiting: incidence and impact on patient quality of life at community oncology settings. Support. Care Cancer 15(5), 497-503 (2007).

3 Haiderali A, Menditto L, Good M, Teitelbaum A, Wegner J. Impact on daily functioning and indirect/direct costs associated with chemotherapy-induced nausea and vomiting (CINV) in a U.S. population. Support. Care Cancer 19(6), 843-851 (2011).

4 Van Laar ES, Desai JM, Jatoi A. Professional educational needs for chemotherapy-induced nausea and vomiting (CINV): multinational survey results from 2388 health care providers. Support. Care Cancer 23(1), 151-157 (2015).

5 Hilarius DL, Kloeg PH, Van Der Wall E, Van Den Heuvel JJ, Gundy CM, Aaronson NK. Chemotherapy-induced nausea and vomiting in daily clinical practice: a community hospital-based study. Support. Care Cancer 20(1), 107-117 (2012).

6 Janelsins MC, Tejani MA, Kamen C, Peoples AR, Mustian KM, Morrow GR. Current pharmacotherapy for chemotherapy-induced nausea and vomiting in cancer patients. Expert Opin. Pharmacother. 14(6), 757-766 (2013).

7 Sommariva S, Pongiglione B, Tarricone R. Impact of chemotherapy-induced nausea and vomiting on health-related quality of life and resource utilization: a systematic review. Crit. Rev. Oncol. Hematol. 99, 13-36 (2016).

8 Shih TYC, Xu Y, Elting LS. Costs of uncontrolled chemotherapy-induced nausea and vomiting among working-age cancer patients receiving highly or moderately emetogenic chemotherapy. Cancer 110(3), 678-685 (2007).

9 Burke TA, Wisniewski T, Ernst FR. Resource utilization and costs associated with chemotherapy-induced nausea and vomiting (CINV) following highly or moderately emetogenic chemotherapy administered in the US outpatient hospital setting. Support. Care Cancer 19(1), 131-140 (2011).

10 Schwartzberg L, Harrow B, Lal LS, Radtchenko J, Lyman GH. Resource utilization for chemotherapy-induced nausea and vomiting events in patients with solid tumors treated with antiemetic regimens. Am. Health Drug Benefits 8(5), 273-282 (2015).

11 National Comprehensive Cancer Network. NCCN Clinical Practice Guidelines in Oncology: Antiemesis-v2.2017 (2017).

- US clinical practice guidelines for the prevention and treatment of chemotherapy-induced nausea and vomiting (CINV).

12 Herrstedt J, Roila F, Warr D et al. 2016 Updated MASCC/ESMO consensus recommendations: prevention of nausea and vomiting following high emetic risk chemotherapy. Support. Care Cancer 25(1), 277-288 (2017).

- European clinical practice guidelines for the prevention and treatment of nausea and vomiting induced by highly emetogenic chemotherapy.

13 Hesketh PJ, Kris MG, Basch E et al. Antiemetics: American Society of Clinical Oncology Clinical Practice Guideline Update. J. Clin. Oncol. 35(28), 3240-3261 (2017).

- US clinical practice guidelines for the prevention and treatment of CINV.

14 Roila F, Warr D, Hesketh PJ et al. 2016 updated MASCC/ESMO consensus recommendations: prevention of nausea and vomiting following moderately emetogenic chemotherapy. Support. Care Cancer 25(1), 289-294 (2017).

- European clinical practice guidelines for the prevention and treatment of nausea and vomiting induced by moderately emetogenic chemotherapy.

15 Ottoboni T, Gelder MS, O'Boyle E. Biochronomer technology and the development of APF530, a sustained release formulation of granisetron. J. Exp. Pharmacol. 6, 15-21 (2014).

- Review of the Biochronomer technology used in granisetron extended-release subcutaneous.

16 Gabrail N, Yanagihara R, Spaczynski M et al. Pharmacokinetics, safety, and efficacy of APF530 (extended-release granisetron) in patients receiving moderately or highly emetogenic chemotherapy: results of two Phase II trials. Cancer Manag. Res. 7, 83-92 (2015).

17 Raftopoulos H, Boccia R, Cooper W, O’Boyle E, Gralla RJ. Slow-release granisetron (APF530) versus palonosetron for chemotherapy-induced nausea/vomiting: analysis by American Society of Clinical Oncology emetogenicity criteria. Future Oncol. 11(18), 1-11 (2015).

18 Raftopoulos H, Cooper W, O’Boyle E, Gabrail N, Boccia R, Gralla RJ. Comparison of an extended-release formulation of granisetron (APF530) versus palonosetron for the prevention of chemotherapy-induced nausea and vomiting associated with moderately or highly 
emetogenic chemotherapy: results of a prospective, randomized, double-blind, noninferiority Phase 3 trial. Support. Care Cancer 23(3), 723-732 (2015).

19 Schnadig ID, Agajanian R, Dakhil SR et al. APF530 (granisetron inj extended-release) in a three-drug regimen for delayed CINV in highly emetogenic chemotherapy. Future Oncol. 12(12), 1469-1481 (2016).

- Phase III trial of granisetron extended-release subcutaneous versus ondansetron, each in a three-drug regimen, for the prevention of delayed CINV in patients receiving highly emetogenic chemotherapy.

20 Sustol (granisetron) extended-release injection, for subcutaneous use, prescribing information. Heron Therapeutics, CA, USA (2016). www.fda.gov/downloads/Drugs/DrugSafety/UCM524796.pdf

21 Navari RM. Treatment of breakthrough and refractory chemotherapy-induced nausea and vomiting. Biomed. Res. Int. 2015, 595894 (2015).

22 Roeland E, Ma J, Binder G et al. Hospitalization costs for nausea and vomiting: a savings opportunity. J. Clin. Oncol. 35(Suppl. 31S), Abstract 155 (2017). 